\section{Habituation and conditioned food aversion}

JOHN R. VOGEL and DONALD E. CLODY

The Squibb Institute for Medical Research, New Brunswick, N.J. 08903

Prior habituation to milk led to a marked deficit in conditioning when milk was paired with injections of atropine methylnitrate. This effect was only partially reversed with repeated conditioning trials.

Novel stimuli typically produce unconditioned suppression, i.e., a disruption of ongoing behavior (Pavlov, 1927). However, when a novel stimulus is repeatedly presented, it gradually loses disruptive properties (Carlton \& Vogel, 1965). This phenomenon is termed habituation (Thompson \& Spencer, 1966). Recent evidence suggests that habituation not only reduces unconditioned suppression to a stimulus, but may also block conditioning to that stimulus (Carlton \& Vogel, 1967; Domjan \& Siegel, 1971; Leaf, Kayser, Andrews, Adkins, \& Leaf, 1968; Lubow \& Moore, 1959; Lubow, 1965; Siegel, 1971).

Recently, considerable attention has been given to the phenomenon of "conditioned food aversion." In these experiments, Ss were first permitted to ingest a food and were then given doses of X-irradiation or a drug that presumably produced sickness (see review by Rozin \& Kalat, 1971). When Ss recovered from the treatment, they exhibited a marked aversion to the food that preceded drug. This study describes an attenuation of food aversion conditioning when Ss were first habituated to the food.

$$
\text { SUBJECTS }
$$

The Ss were 21 adult male Holtzman albino rats and weighed approximately $200 \mathrm{~g}$ at the start of the experiment.

\section{APPARATUS}

The Ss were trained and tested in a $9 \times 8 \times 7.5$ in. box with a Plexiglas top and sides and aluminum end walls. The box was fitted with a glass drinking tube that contained a $33 \%$ solution (room temperature) of sweetened condensed milk (Borden's Star Brand) in tap water. A drinkometer was connected to a programming aparatus and provided a reliable measure of consummatory behavior. PROCEDURE

On Days $1-4,14$ of the Ss were given access to sweetened condensed milk for 2 -h periods in their home cages (habituated groups). Six additional Ss were not treated (not habituated group). On Day 5, food and water were removed from the cages of all Ss. On Day 6, each $\mathrm{S}$ was placed in the apparatus and allowed 100 licks at the drinking tube.

Following completion of 100 licks of milk, all Ss in the "not habituated" drug following completion of either 100 licks or $300 \mathrm{sec}$.

\section{RESULTS}

The mean times to complete 100 licks on each of the test days are shown in Fig. 1. Ss who were not habituated to sweetened condensed milk prior to injection of methylatropine demonstrated an aversion to milk on all test sessions. They took significantly longer to complete 100 licks $(p<.001)$ than did either of the groups that were habituated to milk. However, Ss habituated to milk and then given the drug did not differ from Ss similarly habituated to milk but given injections of water rather than drug. That is, prior experience with milk completely obliterated the effects of a posttraining injection of methylatropine on subsequent milk drinking.

The Ss were not given drug following the first test session (Day 10). In the second test session (Day 11), "not habituated" Ss demonstrated a partial extinction of learned aversion to milk. All Ss were given methylatropine following test sessions on Days 11-15. Repeated administration of drug to Ss habituated to milk led eventually to a

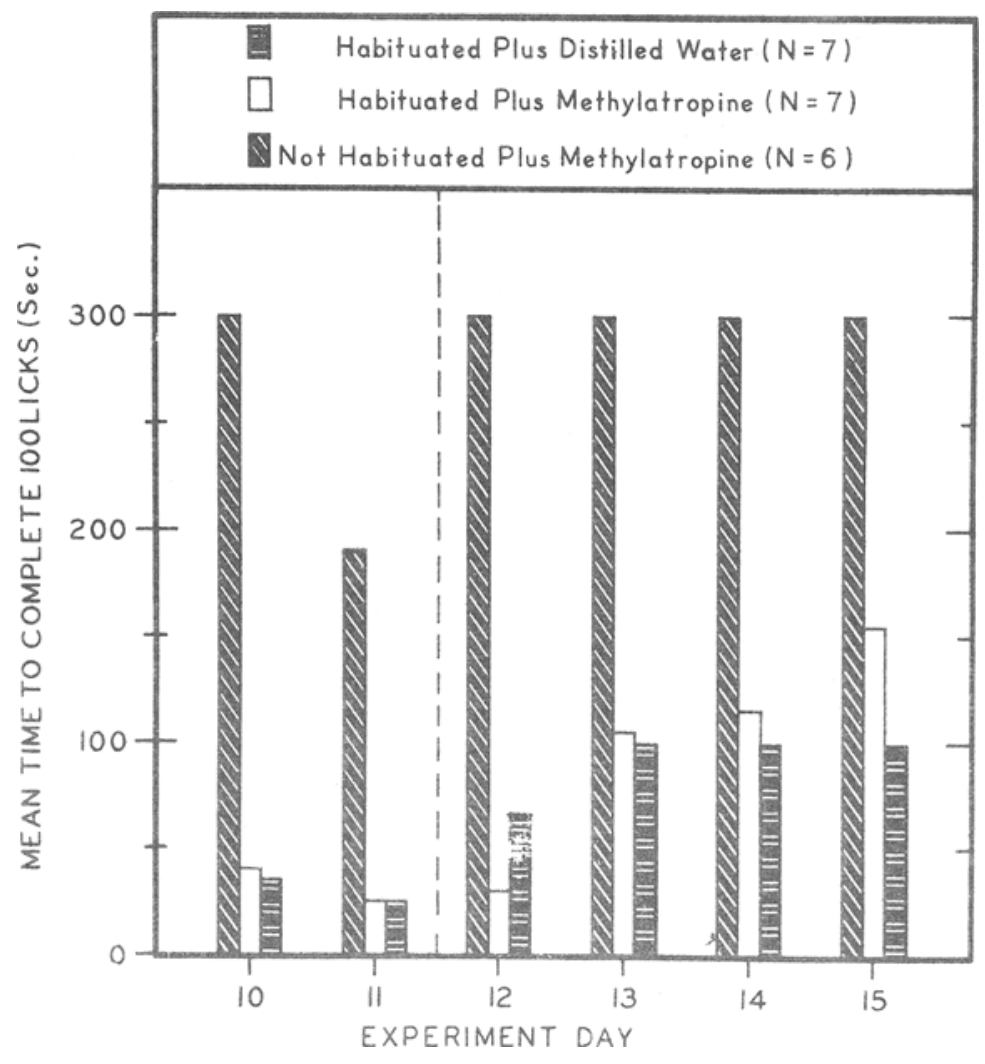

Fig. 1. Effects of habituation to milk and injections of methylatropine following milk consumption on subsequent time to complete 100 licks of milk. All Ss were given methylatropine following sessions on Days 11-15. 
slight lengthening of the time required for them to complete 100 licks, but these scores did not differ from their scores in the first session $(p>.05)$. Similarly, both groups demonstrated significantly $(p<.05)$ less aversion to milk than did Ss "not habituated" but who also received drug (Days 12-15).

\section{DISCUSSION}

Previous studies of conditioned food aversion used treatments that are known to produce nausea and emesis in man. These treatments are presumed to produce nausea in animals as well. They include: X-irradiation (e.g., Smith \& Roll, 1967), apomorphine (e.g., Garcia, Ervin, \& Koelling, 1966), cyclophosphamides (e.g., Wilcoxin, Dragoin, \& Kral, 1971), and lithium chloride (e.g., Malone \& Cox, 1971). Unlike these treatments, methylatropine does not produce nausea, particularly at low doses such as those used in the present experiment. In fact, some atropinic drugs are used to prevent nausea (Goodman \& Gilman, 1965). Another drug that also does not produce nausea, amphetamine, is effective in producing conditioned food aversion (Berger, 1969). These results suggest that drug-induced nausea is not required for the formation of a conditioned food aversion.

Both conditioned food aversion and habituation deficit in conditioning appear to be powerful phenomena. Sweetened condensed milk is a highly preferred food for the rat; yet, following a single association with a low dose of methylatropine, rats avoided the milk. This rapid, powerful conditioning was, however, completely blocked by relatively small amounts of preexposure to sweetened condensed milk. This latter finding agrees with that of previous studies using conditioned food aversion (Rozin \& Kalat, pp. 471) and other single trial conditioning procedures (e.g., Carlton \& Vogel, 1967) and appears even more robust. After five additional training trials, very little conditioning was evident in previously habituated Ss.

\section{REFERENCES}

BERGER, B. D. Retroactive effects of posttrial scopolamine: Possible source of artifacts in "consolidation" experiments. Proceedings of the 77th Annual Convention, APA, 1969, 873-874.

CARLTON, P. L., \& VOGEL, J. R. Studies of the amnesic properties of scopolamine. Psychonomic Science, 1965, 3, 261-262. CARLTON, P. L., \& VOGEL, J. R. Habituation and conditioning. Journal of Comparative \& Physiological Psychology, $1967,63,348-351$.

DOMJAN, M., \& SIEGEL, S. Conditioned suppression following CS pre-exposure. Psychonomic Science, 1971, 25, 11-12.

GARCIA J., ERVIN, F. R., \& KOELLING R. A. Learning with a prolonged delay of reinforcement. Psychonomic Science, 1966, 5, 121-122.

GOODMAN, L. S., \& GILMAN, A. (Eds.)
The pharmacological basis of therapeutics. New York: Macmillan, 1965. P. 538 .

LEAF, R. C., KAYSER, R. J., ANDREWS, J. S. ADKINS, J. W., \& LEAF, S. R. P Block of fear conditioning induced by habituation or extinction. Psychonomic Science, 1968, 10, 189-190.

LUBOW, R: E Latent inhibition: Effects of frequency of nonreinforced pre-exposures of the CS. Journal of Comparative \& Physiological Psychology, 1965, 60, 454-457.

LUBOW R. F \& MOORE, A. V. Latent inhibition: The effect of nonreinforced pre-exposure to the conditional stimulus. Journal of Comparative \& Physiological Psychology, 1959, 52, 415-419.

MALONE, P. E., \& COX, V. C. Development of taste aversions to individual components of gustatory stimuli. Communications in Behavioral Biology, 1971, 6, 341-344.

PAVLOV, I. P. Conditioned reflexes. London: Oxford University Press, 1927.

ROZIN, P., \& KALAT, J. W. Specific hungers and poison avoidance as adaptive specializations of learning. Psychological Review, 1971, 78, 459-486.

SIEGEL, S, Latent inhibition and eyelid conditioning. In A. H. Black and W. F Prokasy (Eds.), Classical conditioning. New York: Appleton-Century-Crofts, 1971

SMITH; J. C., \& ROLL, D. L. Trace conditioning with $\mathrm{X}$-rays as an aversive stimulus. Psychonomic Science, 1967, 9 , 11-12.

THOMPSON, R. F., \& SPENCER, W. A Habituation: A model phenomenon for the study of neuronal substrates of behavior. Psychological Review, 1959 , 52, 415-419.

WILCOXON, H. C., DRAGOIN, W. B., \& KRAL, P. A. Illness-induced aversion in rat and quail: Relative salience of visual and gustatory cues. Science, 1971, 171 . 826-828. 